\title{
Model Pengembangan Wawasan Multikultural bagi Angkatan Kerja
}

\author{
Aris Munandar, Rahmawan Jatmiko, Karlina Maizida \\ Departemen Antarbudaya, Fakultas Ilmu Budaya, Universitas Gadjah Mada \\ Korespondensi: arismunandar@ugm.ac.id
}

\begin{abstract}
The development of New Yogyakarta International Airport is expected to increase the number of inbound tourists. The inbound tourists will bring their cultures into contact with the local culture. A contact between global and local cultures has potential to cause cultural shock and change of values to the local community. Consequently, the local community needs to be aware of the adverse effect of cultural contact, such as the vulnerability of the local values and identity to the hegemony of global culture and identity. Multiculturalism with proper understanding may reduce the adversity the local community faces and in the long run strengthen their local identity and values. Cultivating multicultural understanding can be initiated at the grassroot level among youth by means of exposure to cases of cultural contact. Community engagement program applying simulation is a better model to to build multicultural competence among youth since it brings a closer-to-reality contact situation that stimulates sensible responses to cultural contact.
\end{abstract}

Keywords: cultural contact, changes of values, youth, multicultural setting simulation

\begin{abstract}
Abstrak
Pembangunan New Yogyakarta International Airport diharapkan akan meningkatkan jumlah kunjungan wisatawan mancanegara ke Yogyakarta dan daerah-daerah sekitarnya. Masuknya wisatawan mancanegara ke Yogyakarta akan mengakibatkan kontak budaya lokal dengan budaya global. Kontak tersebut berpotensi menimbulkan gegar budaya dan mengubah nilai-nilai lokal. Oleh karena itu, masyarakat lokal harus menyadari dampak negatif akibat kontak budaya, seperti kerentanan nilai-nilai dan identitas lokal terhadap hegemoni identitas dan nilai-nilai global. Pemahaman mengenai multikulturalisme diharapkan mampu mengurangi dampak negatif yang akan dihadapi masyarakat lokal dan dalam jangka panjang mampu memperkuat identitas serta nilai-nilai lokal. Penanaman kepahaman multikultural dapat dimulai pada kelompok akar rumput di antara kaum muda melalui pajanan terhadap kasus-kasus kontak budaya. Program pemberdayaan masyarakat dengan penerapan metode simulasi merupakan model yang lebih baik untuk menumbuhkan kompetensi multikultural di antara para pemuda karena kaum muda dibawa ke dalam kontak situasi yang mendekati kenyataan, yang dapat merangsang respons yang bijak terhadap kontak budaya.
\end{abstract}

Kata kunci: kontak budaya, perubahan nilai, pemuda, simulasi dengan latar multikultural.

\section{Pendahuluan}

Pembangunan New Yogyakarta International Airport di Kabupaten Kulon Progo akan mendongkrak potensi daerah. Berbagai sektor di wilayah Kulonprogo diprediksi akan berkembang pesat dengan kemudahan akses menuju daerah ini. Arus masuk manusia 
dari berbagai daerah, bahkan dunia, menyebabkan terjadinya kontak antara budaya lokal dan budaya luar yang beragam, yang dapat berpotensi menimbulkan gegar budaya dan perubahan nilai pada masyarakat di wilayah ini.

Kontak antarbudaya harus disikapi secara bijaksana. Perlu upaya khusus agar tidak terjadi perubahan nilai yang mengancam nilai-nilai lokal yang selanjutnya dapat mengakibatkan degradasi moral generasi muda. Oleh karena itu, pemerintah Kabupaten Kulon Progo bersama seluruh masyarakat perlu melakukan upaya penanggulangan yang bersifat preventif, yaitu penguatan identitas lokal sebelum terjadi kontak budaya secara intensif.

Demikian pula potensi yang dimiliki masing-masing individu perlu dikembangkan secara maksimal. Adanya kesempatan, wawasan, motivasi, dan arahan yang tepat sasaran merupakan kombinasi yang dibutuhkan untuk memaksimalkan potensi. Tidak sedikit yang pada awalnya dipandang sebelah mata namun pada akhirnya dapat melejit dan menggapai prestasi tinggi. Sebaliknya, tidak sedikit yang pada awalnya diunggullkan tetapi pada akhirnya tumbang dan putus asa. Hal itu dipengaruhi faktor internal dan eksternal. Faktor internal meliputi motivasi dan wawasan, sedangkan faktor eksternal meliputi kesempatan dan arahan yang tepat sasaran. Jika diberi amanah untuk menyiapkan angkatan kerja yang akan berkontribusi bagi pembangunan daerah, langkah-langkah seperti apa yang harus ditempuh agar mereka dapat melejit dan menggapai prestasi?

Dinas Tenaga kerja dan Transmigrasi (Disnakertran) merupakan lembaga pemerintah di tingkat kabupaten yang diberi tugas dan tanggung jawab untuk mengembangkan potensi angkatan kerja agar menjadi tenaga kerja yang tidak sekadar terampil, tetapi juga memiliki kepribadian yang kuat. Setiap tahun, ribuan pemuda memasuki tahapan menjadi angkatan kerja. Potensi yang dimiliki siap untuk dikembangkan agar menjadi sumber daya manusia yang cakap.

Kabupaten Kulon Progo sedang berbenah menyambut kehadiran Bandara Internasional Yogyakarta (New Yogyakarta International Airport, NYIA). Persiapan dalam cakupan yang sempit adalah memenuhi kebutuhan Sumber Daya Manusia bagi bandara dan dalam cakupan yang luas adalah menyiapkan Sumber Daya Manusia untuk sektor-sektor lain yang terdampak oleh keberadaan bandara Internasional. Sebagian tugas dan tanggung jawab penyiapan SDM didelegasikan kepada Disnakertran.

\section{Keadaan Ketenagakerjaan Kulon Progo Terkini}

Keadaan ketenagakerjaan Kabupaten Kulon Progo memberikan gambaran mengenai volume tugas dan tanggung jawab yang harus dilaksanakan oleh Disnakertrans. Data dari Disnakertrans Kulon Progo menunjukkan bahwa jumlah angkatan kerja per Agustus 2017 mencapai 244.415 (74,61\% dari total penduduk usia kerja). Penduduk yang sudah bekerja sebanyak 239.542 (98\%), sedangkan yang belum bekerja sebanyak 4.873 (2\%). (Lihat Ilustrasi 1). Untuk membantu meningkatkan kualitas 4.873 angkatan kerja tersebut sehingga dapat meraih kesempatan kerja diperlukan kerja keras, apalagi target capaiannya tidak sekadar menyiapkan mereka menjadi terampil, tetapi juga cakap.

\section{Angkatan Kerja yang Cakap}

Angkatan kerja yang cakap akan mampu memberikan kontribusi yang besar bagi 


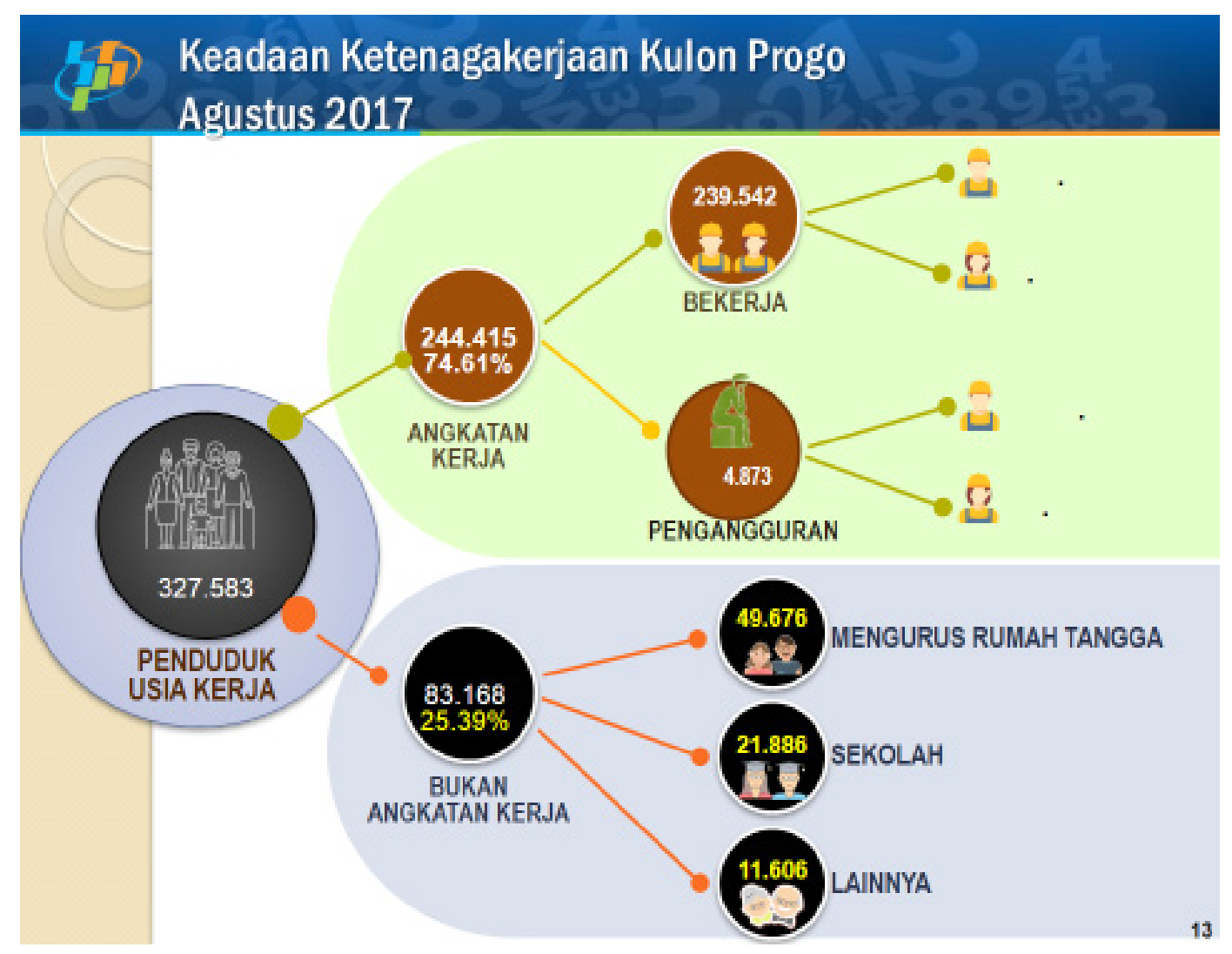

Ilustrasi 1. Keadaan Ketenagakerjaan Kabupaten Kulon Progo pada Agustus 2017. (Sumber: Disnakertrans Kulon Progo, 2017)

pembangunan daerah. Namun, untuk menjadi "cakap" harus melalui proses yang dirancang dengan matang. Persyaratan utama yang harus terpenuhi adalah memiliki wawasan multikultural karena pada era global sekarang ini, pergaulan hampir tidak terbatas, baik dalam hal cakupan geografisnya, jumlah orangnya, maupun keragaman budayanya. Wawasan multikultural memberikan pengetahuan kepada seseorang mengenai budaya sendiri, budaya yang lain, dan interaksi antara budaya sendiri dan budaya lain yang saling menguntungkan. Dengan wawasan multikultural tersebut seseorang tidak menjadi sombong dan lebih menghargai orang lain serta tidak rendah diri dan memiliki martabat sehingga sejajar dengan orang lain. Ia memiliki kebanggaan terhadap budaya sendiri sekaligus terbuka terhadap kebudayaan lain sehingga dapat saling memperkaya kebudayaan dengan hal-hal positif dari kebudayaan lain.

\section{Model Pengembangan Wawasan Multikultural}

Wawasan multikultural terbentuk melalui pengalaman-pengalaman berinteraksi dengan berbagai kalangan yang beragam latar belakang budayanya, dalam rentang waktu yang cukup lama. Dalam lingkungan seperti itu, kepekaan untuk melihat perbedaan dan persamaan akan terasah, sikap-sikap saling menghargai akan terbentuk, dan akhirnya tidak mudah mengalami gegar budaya ketika menemui hal-hal lain yang jauh berbeda dengan yang biasa dialaminya. Seseorang yang mampu mengembangkan sikap seperti 
ini akan mampu menjadi pengayom dan panutan bagi lingkungan sekitarnya.

Kesempatan berinteraksi dalam situasi sosial budaya yang heterogen akan dapat diperoleh dengan migrasi ke masyarakat budaya yang berbeda atau berada dalam forum-forum internasional, baik di lingkungan sendiri maupun di luar lingkungannya. Akan tetapi, melakukan hal-hal tersebut-migrasi dan berpartisipasi dalam forum internasional—tidak selalu mudah, antara lain, karena mahal. Pada kenyataannya, membentuk wawasan multikultural sangatlah penting. Pembangunan daerah yang akan membuka kontak antarbudaya jika tanpa dukungan SDM yang berwawasan multikultural akan menimbulkan masalah-masalah sosial budaya yang menghambat perubahan sosial ke arah yang diharapkan.

Solusi alternatif untuk menciptakan suatu keadaan yang bersifat multikultural sebagai arena pembelajaran wawasan multikultural adalah melalui simulasi yang dipandu oleh narasumber yang memiliki wawasan multikultural. Narasumber tersebut akan mampu memberikan pemahaman terhadap konsep-konsep penting terkait wawasan multikulturalisme, memberikan simulasi yang sedekat mungkin dengan realitas, dan memberikan masukan balik kepada peserta. Model pengembangan wawasan multikultural seperti ini diharapkan dapat dilakukan di berbagai tempat dengan biaya yang relatif murah, dengan cara yang relatif mudah dan cepat serta dengan luaran yang berkualitas.

\section{Pengabdian kepada Masyarakat Berbasis Wawasan Multikultural bagi Angkatan Kerja}

Departemen Antarbudaya Fakultas Ilmu Budaya menyelenggarakan program Pengabdian kepada Masyarakat dengan menerapkan model simulasi pengembangan wawasan multikultural bagi angkatan kerja di Kabupaten Kulon Progo bekerja sama dengan Dinas Tenaga Kerja dan Transmigrasi Kabupaten Kulon Progo. Kegiatan dilaksanakan pada 13 Oktober 2018 di Balai Latihan Kerja kabupaten Kulon Progo, diikuti oleh 67 angkatan kerja yang sedang mengikuti program pelatihan Office Tools, Desain Grafis, Pengolahan hasil Pertanian, dan lain-lain. Berikut ini diuraikan tahapan-tahapan penyelenggaraannya, yang meliputi persiapan, pelaksanaan, evaluasi, dan perbaikan.

\section{Tahap Persiapan}

Rancangan program Pengabdian kepada Masyarakat disusun oleh Tim PkM Departemen Antarbudaya yang melibatkan dosen dan mahasiswa program Magister. Penentuan lokasi dan peserta dilakukan dengan mempertimbangkan masukan dari mitra kerja sama, yaitu Dinas Tenaga Kerja dan Transmigrasi Kabupaten Kulon Progo. Pada Oktober 2018 tengah berlangsung berbagai program pelatihan reguler bagi angkatan kerja di Balai Latihan Kerja Kulon Progo. Berdasarkan pertimbangan efisiensi dan efektivitas penyelenggaraan, program PkM diselenggarakan pada 13 Oktober 2018 di Balai Latihan Kerja Kulon Progo. Penyelenggaraan PkM pada hari Sabtu tidak mengganggu kegiatan pelatihan yang tengah berjalan dan pemanfaatan tempat di BLK memudahkan peserta untuk hadir mengikuti Program PkM. Selanjutnya, Tim PkM melakukan persiapan materi dan Disnakertrans melakukan persiapan untuk tempat dan menghadirkan peserta. 


\section{Tahap Pelaksanaan}

Kegiatan PkM berlangsung selama lima jam, dimulai pada pukul 09.00 hingga 14.00 WIB. Simulasi Model Pengembangan Wawasan Multikultural dilakukan dalam empat sesi, masing-masing dengan muatan materi sebagai berikut.

1. Pembangunan Ketenagakerjaan

2. Pengembangan Diri dan Kepribadian

3. Dampak Globalisasi

4. Penguatan Identitas Lokal.

Simulasi diawali dengan pemaparan tentang materi-materi tersebut untuk memberikan latar pengetahuan yang memadai sebelum peserta melakukan diskusi.

Muatan materi Pembangunan Ketenagakerjaan Kabupaten Kulon Progo bertujuan memberikan konteks pentingnya pengembangan kualitas angkatan kerja yang cakap. Komitmen pemerintah daerah terhadap pembangunan ketenagakerjaan diwujudkan, antara lain, dalam program akselerasi SDM untuk produktivitas. Program Akselerasi SDM ini merupakan langkah strategis pemerintah untuk menyiapkan SDM pendukung operasionalisasi Bandara Internasional Yogyakarta yang ditargetkan dibuka pada 2019. Komitmen pemerintah harus didukung oleh kesungguhan angkatan kerja untuk meningkatkan potensi yang ada dalam dirinya. (lihat Ilustrasi $2 \& 3$ ).

Muatan materi yang kedua, Pengembangan Diri dan Kepribadian, bertujuan memberikan pemahaman mengenai sifat dan kepribadian yang positif, yang akan menjadikan seseorang sebagai individu yang cakap. Peserta diperkenalkan dengan strategi pengembangan diri. (lihat Ilustrasi 4).

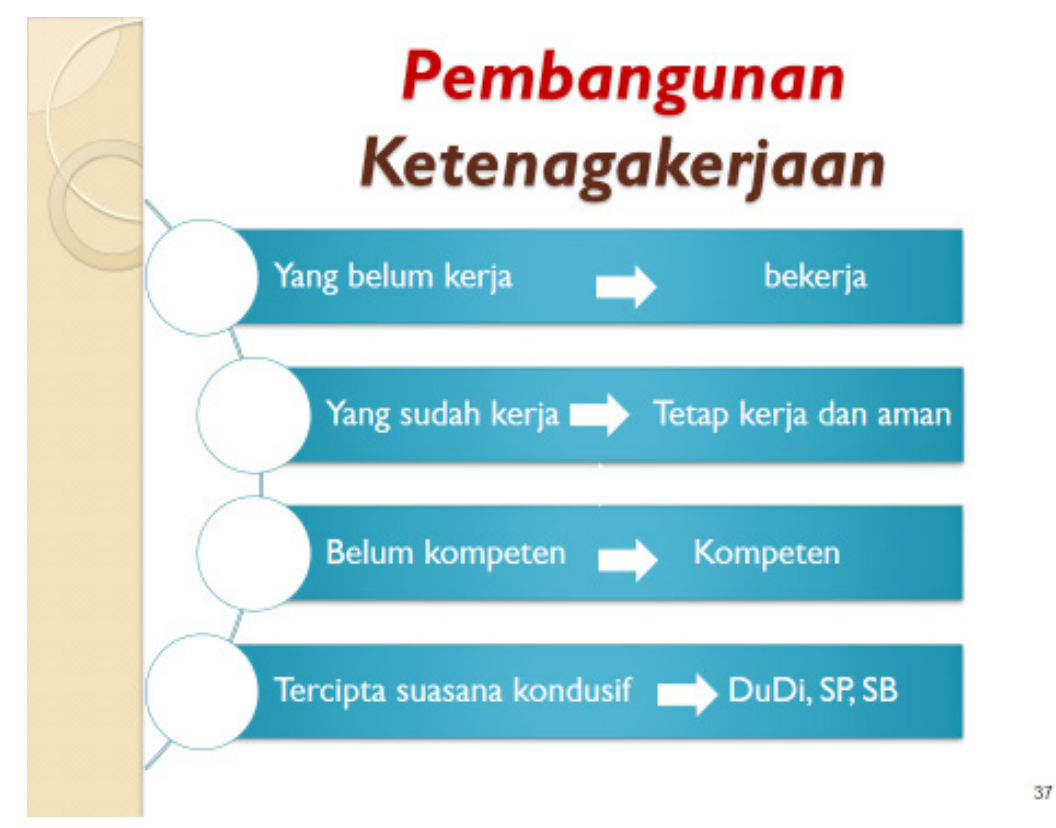

Ilustrasi 2. Kebijakan Ketenagakerjaan Kabupaten Kulon Progo. (Sumber: Disnakertrans Kulon Progo, 2017) 


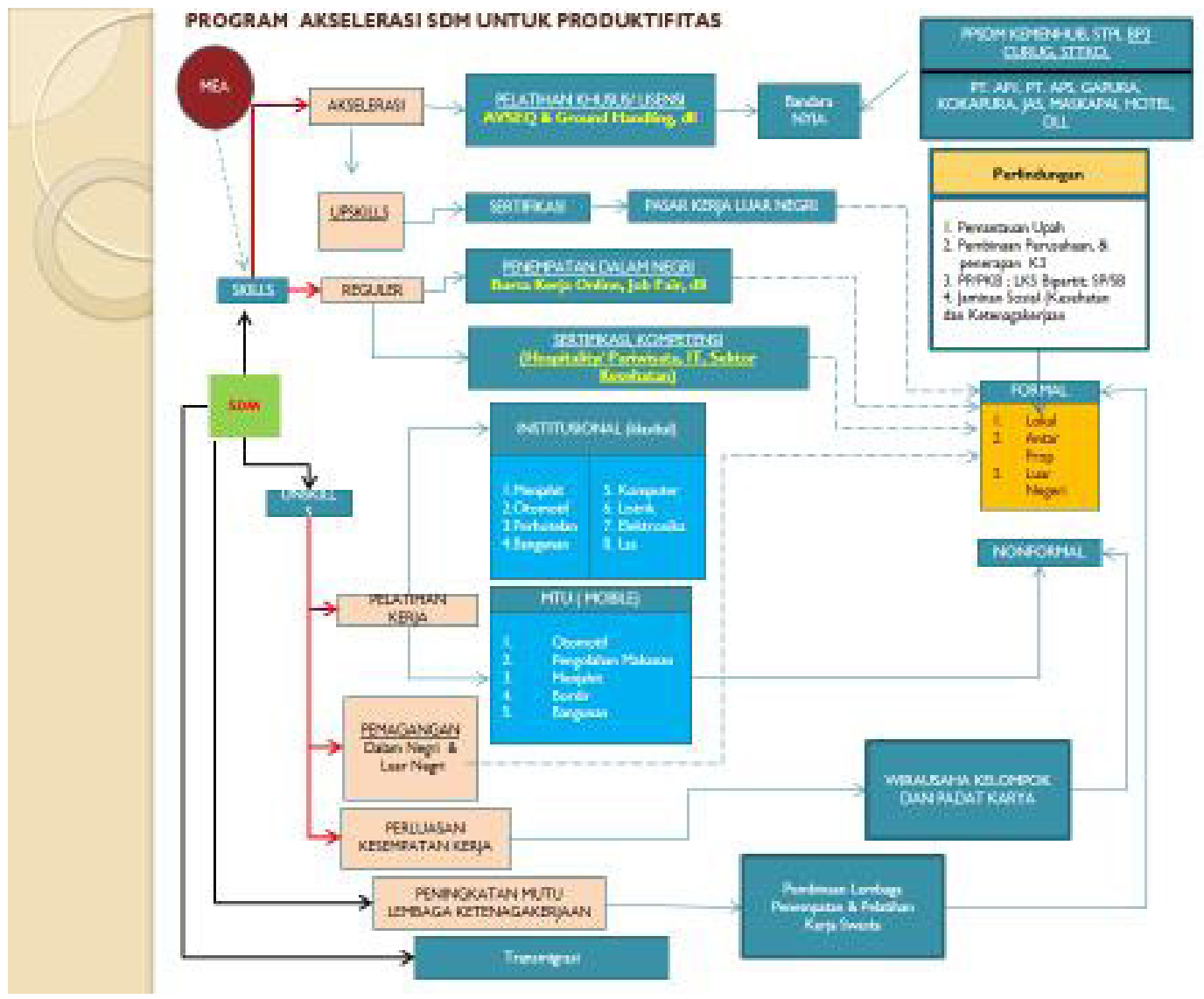

Ilustrasi 3. Program Akselerasi SDM untuk Produktivitas. (Sumber: Disnakertrans Kulon Progo, 2017)

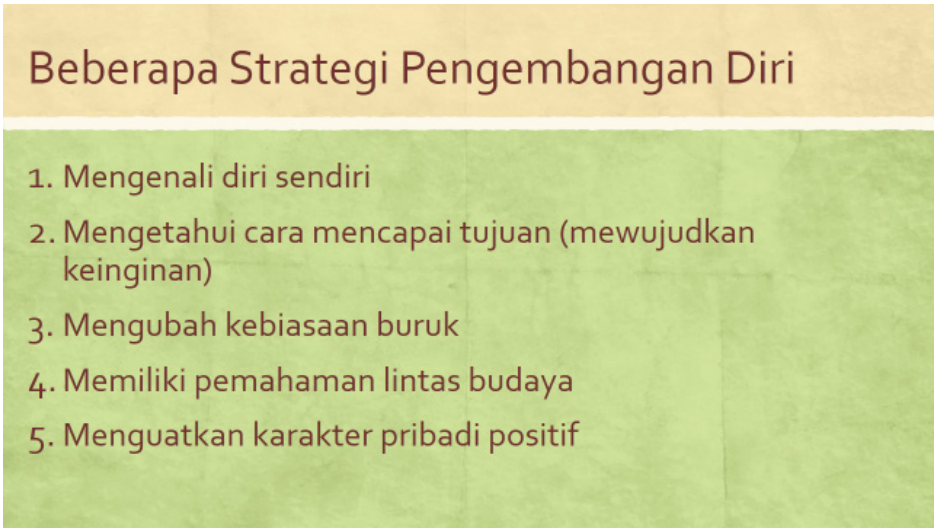

Ilustrasi 4. Strategi Pengembangan Diri. (Sumber: PkM Dep. Antarbudaya FIB UGM, 2018)

Muatan materi ketiga, Dampak Globalisasi, bertujuan membangun sikap yang terbuka dan kritis terhadap dinamika sosial yang cepat akibat globalisasi. Globalisasi memiliki dua sisi: peluang dan ancaman. Oleh karena itu, setiap individu harus mampu menggunakan kekuatan-kekuatan yang ada dalam dirinya untuk memanfaatkan peluang dan menepis ancaman. 


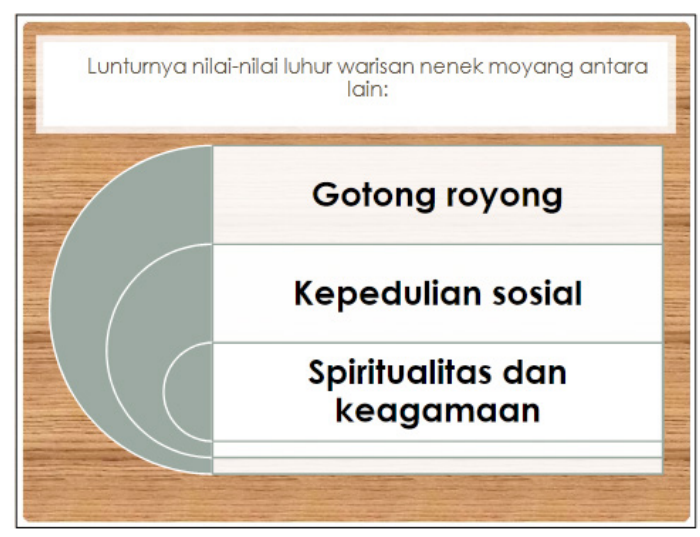

Ilustrasi 5. Dampak Globalisasi. (Sumber: PkM Dep. Antarbudaya FIB UGM, 2018)

Muatan materi keempat, Penguatan Identitas Lokal, bertujuan membangun sikap loyalitas terhadap kearifan-kearifan lokal yang merupakan bagian dari identitas bangsa. Di tengah arus deras globalisasi, masyarakat akan berhadapan dengan berbagai macam pengaruh yang datang dari luar yang tidak selalu selaras dengan kearifan-kearifan lokal. Oleh karena itu, dibutuhkan kekuatan untuk tetap berakar pada budaya lokal sehingga tidak terbawa arus globalisasi yang semakin deras.
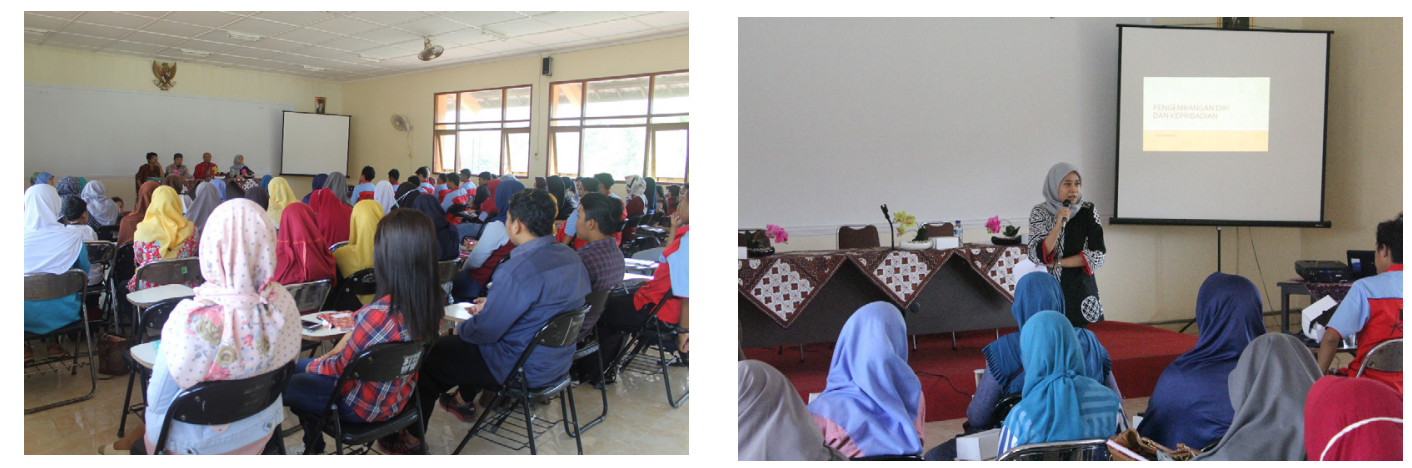

Ilustrasi 6 dan 7. Penyampaian Materi Kebijakan Pengembangan Ketenagakerjaan dan Pengembangan diri dan Kepribadian. (Sumber: PkM Dep. Antarbudaya FIB UGM, 2018)
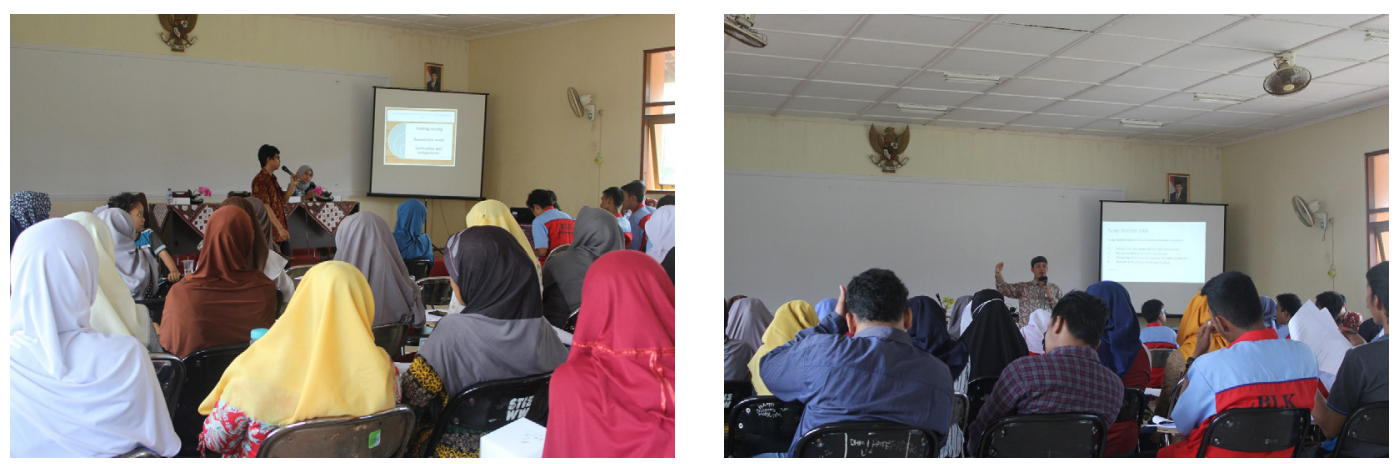

Ilustrasi 8 dan 9. Penyampaian Materi Dampak Globalisasi dan Pemertahanan Identitas Lokal. (Sumber: PkM Dep. Antarbudaya FIB UGM, 2018) 


\section{Tahap Evaluasi}

Evaluasi menitikberatkan pada aspek efisiensi dan efektivitas program. Beberapa hal berikut ini perlu dilakukan untuk penyempurnaan Simulasi Pengembangan Wawasan Multikultural pada program PkM selanjutnya.

1. Penambahan materi visual (video) untuk memberikan gambaran yang lebih konkret terhadap isu-isu globalisasi, konflik sosial budaya, ataupun sifat dan kepribadian yang positif.

2. Pembagian peserta menjadi kelompok-kelompok yang lebih kecil (10 orang) dengan pendamping untuk memberikan kesempatan berdiskusi secra lebih intensif.

3. Peserta pengabdian merupakan calon PMI (Pekerja Migran Indonesia) yang akan dikirim ke luar negeri karena mereka lebih rentan terhadap gegar budaya dan tercerabutnya nilai-nilai budaya lokal.

\section{Kesimpulan}

Wawasan multikultural merupakan prasyarat bagi keberhasilan pembangunan Sumber Daya Manusia pada era Globalisasi. Sikap menutup diri akan menyebabkan suatu budaya terlindas oleh desakan budaya lain yang sangat kuat. Sebaliknya, sikap yang permisif dengan membiarkan semua unsur budaya lain masuk akan menghilangkan kearifan-kearifan lokal yang telah terbukti mampu membawa masyarakat melintasi berbagai zaman. Dengan wawasan multikultural, masyarakat dapat bersikap objektif dalam memandang perbedaan dan persamaan antarbudaya. Hal-hal yang positif pada budaya lain dapat diadopsi untuk semakin memperkaya budaya sendiri, sedangkan halhal yang tidak sesuai dapat ditangkal. Keadaan ini akan membawa masyarakat pada kualitas kehidupan yang lebih baik.

\section{Daftar Pustaka}

Disnakertrans Kulon Progo. (2017). "Pembangunan Ketenagakerjaan Kabupaten Kulon Progo" dalam Kebijakan Ketenagakerjaan Kabupaten Kulon Progo. Kulonprogo. Tidak diterbitkan.

Jatmiko, Rahmawan. (2018) “Dampak Globalisasi”. Yogyakarta: PKM Departemen Antarbudaya FIB UGM.

Maizida, Karlina. (2018). "Pengembangan Diri dan Kepribadian”. Yogyakarta: PKM Departemen Antarbudaya FIB UGM.

Munandar, Aris. (2018). “Pemertahanan Identitas Lokal”. Yogyakarta: PKM Departemen Antarbudaya FIB UGM. 